\title{
The design and performance evaluation of assisted chip removal system in helical milling of CFRP/Ti stacks
}

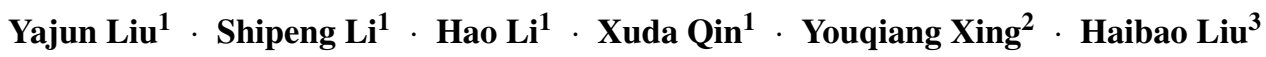

Received: date / Accepted: date

\begin{abstract}
Hybrid structures consisting of carbon fiber reinforced plastics(CFRP) and metal have been widely applied in aircraft manufacturing. Numerous holes need to be made in order to assemble the structures. Due to the small size of CFRP chips and the dry cutting conditions, improperly dealing with chips can increase tool wear, degrade hole quality and contaminate to environment and health. In this study, an assisted chip removal system, mainly including an exhaust hood, a vacuum cleaner and a tool holder, was used for helical milling of CFRP and titanium alloys (CFRP/Ti stacks). The geometry of the chip exhaust hood model was designed and optimized to clear and collect cutting chips using finite element method (FEM). Based on this system, pressurized air was pumped into cutting areas through the inner cooling channels in the tool. Then the performance of the assisted chip removal system was evaluated in helical milling of CFRP/Ti stacks under different chip collecting conditions. Results showed that this system had a good ability of chip removal and preventing chips returning into the hole. And the pressurized air could promote chips remained in the hole to be removed and provide cooling effect to cutting tool. As a result, tool wear was reduced, the cutting force and cutting temperature were decreased and hole quality was improved. Results proved the assisted chip removal system can help to further improve the hole-making process of CFRP/Ti stacks.
\end{abstract}

\footnotetext{
${ }^{1}$ Key Laboratory of Mechanism Theory and Equipment Design of Ministry of Education, Tianjin University, 300350 Jinnan, Tianjin, PR China.

Tel.: +86-17612288127

\ shipengli@tju.edu.cn

${ }^{2}$ School of Mechanical Engineering, Southeast University, Nanjing, People's Republic of China

${ }^{3}$ Department of Mechanical Engineering, Imperial College London, South Kensington Campus, London SW7 2AZ
}

Keywords chip exhaust hood; helical milling; CFRP; titanium alloy; chip removal system

\section{Introduction}

Hybrid structure consisting of CFRP/Ti stackscan combine their respective advantages while avoiding the weaknesses of each material [1].Therefore, this kind of stacks are widely used in aircraft manufacturing as main load-bearing structure [2-5]. CFRP/Ti need to be drilled integrally to improve the hole accuracy and drilling efficiency. However, the machining difficulties of CFRP/Ti stacks and the huge different properties between them pose big challenges to hole-making technologies.

The method of dealing with chip has a great impact on holemaking process [6]. CFRP produce tiny particle-like chip, while titanium alloys produce continuous chip[7]. The particles produced by CFRP can suspend in the air and contaminate work environment. ZHANG et al. [8]conducted an experiment on rats exposed to the chip of carbon fiber and carbon fiber composite. They confirmed that composite material can influence the respiration systems of the rats. Besides, the chip remained in the hole can decrease hole quality. Nan et al.[9] proved that the chip of titanium alloys caused damage to the hole surface of CFRP, leading to a high surface roughness. Moreover, the residual chip in the hole would participate in the cutting process and exacerbate tool wear[10]. However, now the hole-drilling in aircraft assembly is commonly dry cutting without any chip removal assisted system. Therefore, effective chip extraction measures are necessary for clean manufacturing and good hole quality. Helical milling, as a promising hole-making process, has been studied widely. The tool in helical milling participates in three movements: rotation, revolution and axial feed, as shown as in Fig. 1. There is an eccentric distance between the tool 
axis and the hole axis. Compared to conventional drilling, helical milling has smaller thrust force, superior heat dissipation, better chip removal and high flexibility [11-14]. Many studies have proved that helical milling is particularly suitable to be used in the hole-making process of CFRP/metal stacks [15, 16].Helical milling have better chip removal ability and can avoid the damage to CFRP caused by titanium alloy chip owing to its discontinuous cutting process. But the eccentric distance between tool and hole could lead to more chip remaining in the hole. More importantly, chip that have been moved out could return to the hole if not being cleaned up promptly. This problem is more obvious in machining of vertical holes.Bad chip removal conditions also can lead to high cutting temperate[17]. So appropriate method that can help chip to be removed from the hole and provide prompt chip collecting can contribute to decreasing tool wear and increase hole quality.

There have been a few studies involving in chip formation and the chip exhaust hood in CFRP machining. Zheli[18] compared two different chip removal process of chip and rod by experiments, the results indicates certain vibration amplitude can improve removal effects of chip. Liu M [19]studied the process of chip formation under various cutting conditions. It clarified that the chip removal was improved greatly in air blow and MQL drilling. PETER S et al. [20]conducted several experiments to compare the performance of five different chip exhaust hood methods. Bi et al.[21] designed a chip exhaust hood using COSMOSFLOWORKS. However, these studies are aimed at conventional drilling or milling process and few research is enhancing chip removal ability in the hole. The design method is currently mainly based on experience or merely experiments. And further experiments need to be conducted to validate the performance of the chip exhaust hood model. In this paper, an assisted chip removal system was designed for helical milling of CFRP/Ti stacks. The geometry of the chip exhaust hood was optimized using FEM. And the performance of the exhaust hood with pressurized air pumped into the hole was evaluated. The influences of different chip collecting conditions on cutting force, cutting temperature, tool wear and hole quality were discussed. Results can help to further improve the holemaking process of CFRP/Ti stacks.

\section{Design of the exhaust hood}

\subsection{Work principle of the exhaust hood}

The design of the chip removal system and its work principle are illustrated in Fig. 2. It can be basically divided into three parts: the exhaust hood, the vacuum cleaner and the air pump. The air pump generates pressurized air and makes it flow into the cutting area through the cooling inner channels of the tool holder and the cutting tool. The pressurized air would accelerate chip to be removed from the hole. The vacuum cleaner provided sufficient negative pressure to collect the chip from the hole and ensure no chip escape into the work environment. The exhaust hood is installed on the tool holder. The hood geometry parameters have a significant influence on the chip removal and chip collection, which need to be studied and optimized.

\subsection{Modeling of the chip exhaust hood}

The chip exhaust hood was installed on the tool holder. Its top part should be able to fit the tool holder well. Therefore, the part in Position 1 (as shown in Fig. 3a) is designed to achieve this aim. The part in Position 2(as shown in Fig. $3 b$ ) is for fastening the hood to machine tool holder. Furthermore, the angle $\left(^{\circ}\right)$ and height $(\mathrm{mm})$ of the outlet, the angle $\left({ }^{\circ}\right)$ and height $(\mathrm{mm})$ of the inlet and the distance between hood and workpiece (gap distance), were selected to optimize the hood geometry, as shown in Fig. 3.

The geometry of the chip exhaust hood has a considerable influence on its performance of removing chips. According to the geometries of the tool holder and the cutting tool used in this paper, the dimensions of the chip exhaust hood were determined and listed in Table 1. The goal of chip exhaust hood optimization is to accelerate the removal of the chip removal from the hole and prevent chip from escaping into the surroundings. In the simulation model, the flow velocity of air at the hole entrance (Circumferential surface 1 in Fig. 4), which is named as removal velocity, can reflect the capability of chip removal system in removing the chip from the hole. While the flow velocity of air near the gap between the hood and the workpiece (Circumferential surface 2, in Fig. 4), which is named as collecting velocity, can represent the capability of the chip removal system in preventing chip escape and collecting chip, which is named as collecting velocity. These two velocities were used as the indicators for the hood performance. The bigger the removal velocities and collecting velocities are, the better the hood performance. By comparing the FEM simulation results under different model sizes, the model parameters with good performance of collecting and removal chip are optimized.

In this paper, the density of the fluid air in the flow field changes little, which can be regarded as low-speed and incompressible flow. Therefore, the pressure solver is selected. The turbulence model and the standard k-e two equation model are applied. Taking the air space of the model as the simulation area to divide the volume mesh of each individual. For the upper cylinder part(1), the Hex and Wedge method is used with the mesh size of 5; For outlet of model, the Tet and Hybrid method is used with the mesh size of 3 ; for the inlet of model, Tet and Hybrid method is use 


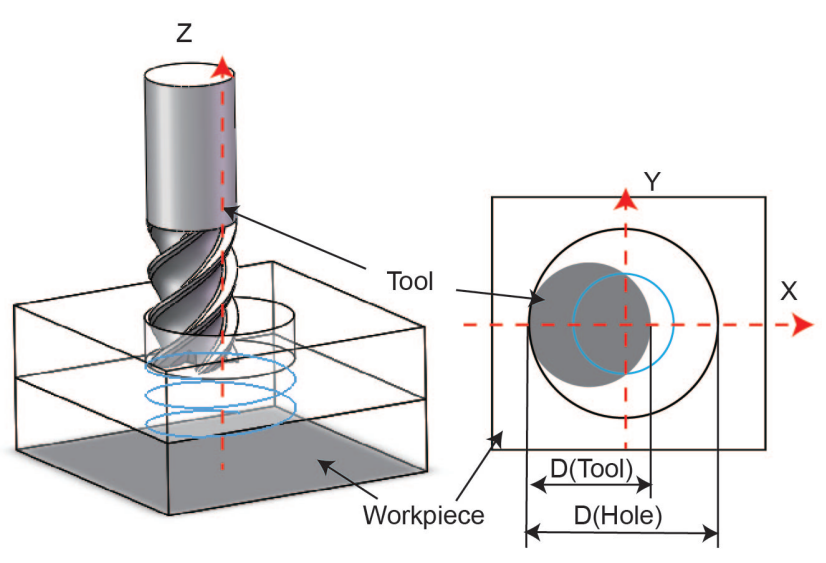

Fig. 1 Working principle of Helical milling

Table 1 Series values of the additional design parameters

\begin{tabular}{lllllllll}
\hline Parameters & range & \multicolumn{7}{c}{ series } \\
\hline Angle of inlet $\left(^{\circ}\right)$ & $0-80$ & 10 & 20 & 40 & 60 & 90 & 110 \\
Angle of outlet $\left(^{\circ}\right)$ & $0-80$ & 20 & 0 & 40 & 60 & & \\
Height of inlet $(\mathrm{mm})$ & $0-26$ & 9 & 12 & 15 & 18 & 21 & 24 \\
Height of outlet $(\mathrm{mm})$ & $28-53$ & 34 & 38 & 42 & 46 & 50 & 54 \\
Gap distance & $\geq 13$ & 15 & 18 & 21 & 24 & 27 & 30 \\
Depth of holes & $0-12$ & 2 & 4 & 6 & 8 & 10 & 12 \\
\hline
\end{tabular}

with the mesh size of 1 .The boundary conditions are consistent with the experimental conditions: Inlet air pressure is set to 0.5 bar, Intensity and Hydraulic Diameter is 4.385 $\%$ and 0.08936 . The outlet air pressure is 1.5 bar, Intensity and Hydraulic Diameter is $3.392 \%$ and 0.05 respectively.. The model body part is set as wall.The simulation process are shown in Fig 5

\subsection{Simulation of the chip exhaust hood}

Fig. 6 shows the simulation results obtained from chip removal systems with different hood parameters. A higher outflow velocity in surface 1 can enhance chip removal and a higher inflow velocity in surface 2 can help to prevent chip escaping. The hood parameters should be optimized to increase the air velocities both in the surfaces 1 and 2 . It can be seen that the air velocity at these two surfaces increased as the heights of the inlet and the outlet increases, while decreased as the angel of the outlet and gap distance between the exhaust hood and workpiece increases. And air velocity at the surfaces 1 and 2 increased in the beginning, and then deceased as the angel of inlet and depth increases. Based on the simulation results ,the optimization was conducted on the chip exhaust hood and the optimal parameters were shown in Table. 2.
Table 2 Series values of the additional design parameters

\begin{tabular}{cc}
\hline Parameters & optimal results \\
\hline Angle of inlet $\left(^{\circ}\right)$ & 40 \\
Angle of outlet $\left(^{\circ}\right)$ & 20 \\
Height of inlet $(\mathrm{mm})$ & 24 \\
Height of outlet $(\mathrm{mm})$ & 38 \\
Gap distance & more than 15 \\
Depth of holes & 2 \\
\hline
\end{tabular}

\section{Experimental}

CFRP and titanium alloy (Ti6Al4V) were chosen for drilling. The diameter of the holes is $10 \mathrm{~mm}$ and the holes are drilled by a tool with a diameter of $6 \mathrm{~mm}$, which is designed specifically for helical milling. Details corresponding to the tool are listed in Table 3. In this study, a Kistler three-direction stationary dynamo-meter (9257A) was utilized to gather cutting force signals. The supporting multi-channel charge amplifier Kistler (type 5070) and the signals were recorded on a personal computer. The number of holes is 13. The experimental conditions are provided in Table 4 . The chip exhaust hood was manufactured by a 3D printer, according the optimized geometry in Table 2. The top part of the machine object was unidirectionalCFRP plate $(5 \mathrm{~mm}$ thick, consisting of T800 carbon fiber ), while the bottom part was titanium alloy plate $(10 \mathrm{~mm}$ thick, Ti-6Al-4V). The diameter of machined holes was $10 \mathrm{~mm}$.Cemented carbides (WC-12\%Co) milling tools were used and there were two inner cooling channels in the tool so that the pressurized air can be pumped into the cutting areas, as shown as in Fig. 7. Other details of the cutting tool are listed in Table 3. A Kistler three-direction stationary dynamometer (9257A) was utilized to gather cutting force signals. The supporting multichannel charge amplifier Kistler (type 5070) and the signals were recorded on a computer. The cutting conditions are provided in Table 4. To evaluate the performance of the exhaust hood system, helical milling experiments were conducted under different chip conditions, There are three chip removal conditions used in helical milling experiments: exhaust hood system with pressurized air cooling(ESA), only exhaust hood system without air cooling(ES); wihout exhaust hood system or air cooling(NES).,details as shown in Table 5 and Fig. 8. Holes were produced under each condition using a new tool with the same geometry. The working principle of cutting force and temperature are shown in Fig.9.

\section{Results and Discussion}

\subsection{Chip collecting ability}

Fig. 10 shows the pictures on the hole entrance under different chip removal conditions. It can be seen that the chip, 


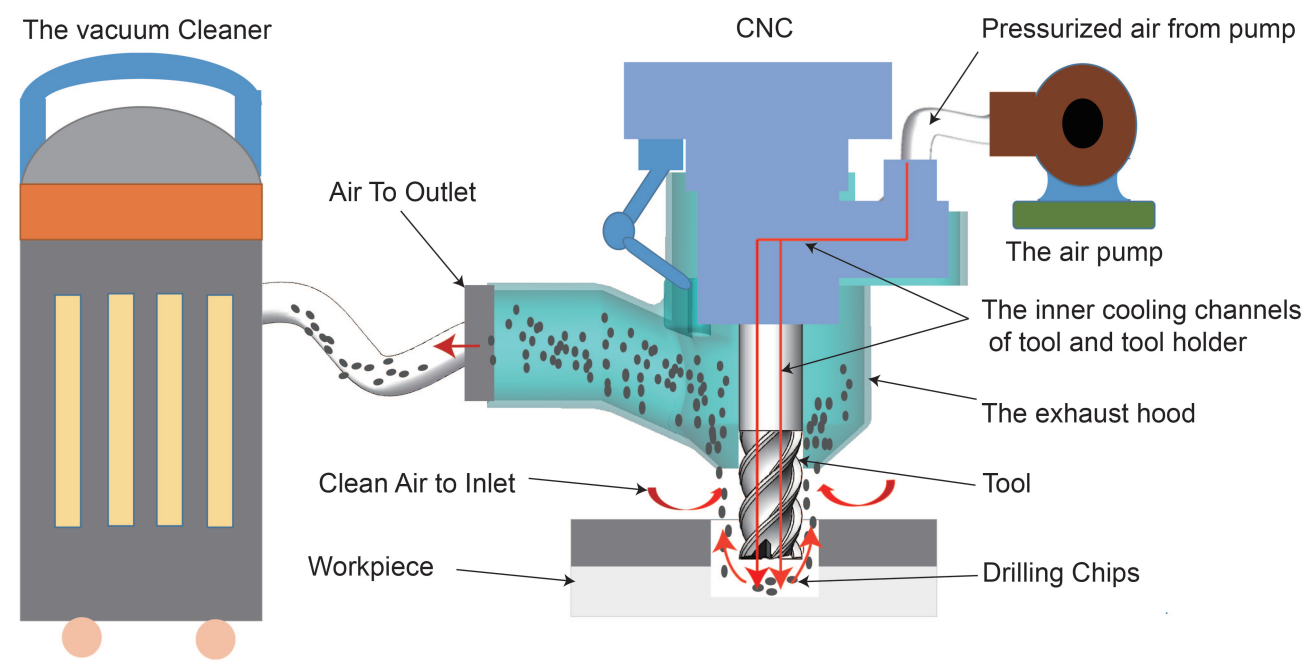

Fig. 2 Working principle of the exhaust hood

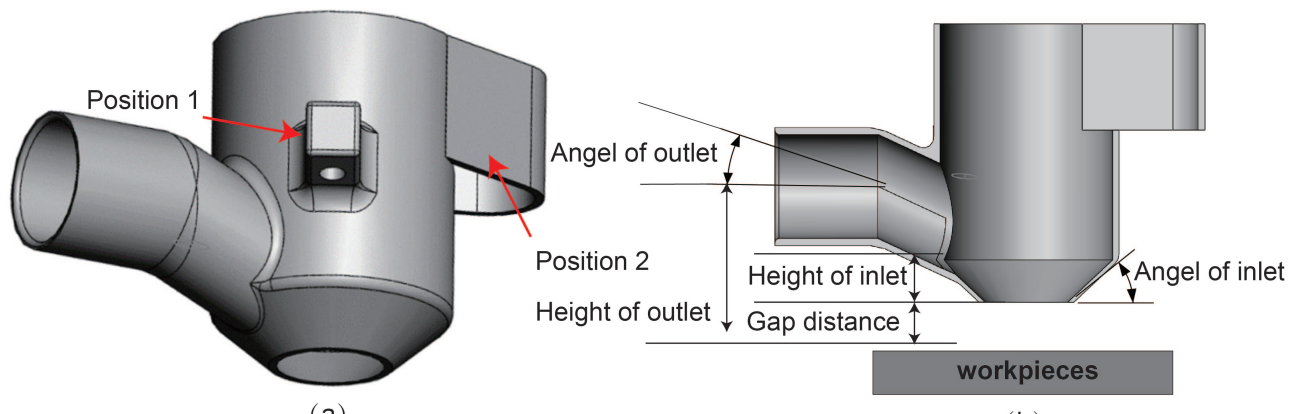

(a)

(b)

Fig. 3 Model parament of the exhaust hood

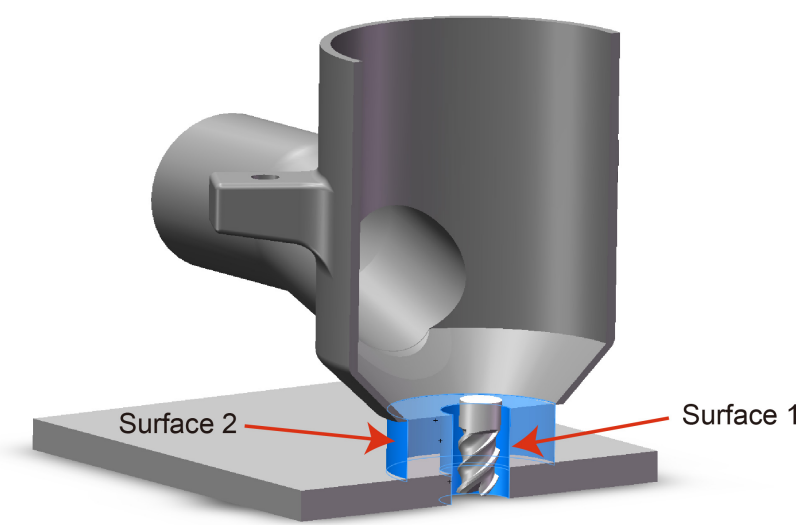

Table 4 experimental conditions

\begin{tabular}{ll}
\hline conditions & \multicolumn{1}{c}{ Details } \\
\hline Materials & $\begin{array}{l}\text { CFRP (T800 5 mm thick) and Titanium Alloy } \\
\text { (Ti6A14V 10 mm thick) }\end{array}$ \\
cutting tool & $\begin{array}{l}\text { Hanland XK714D NCPC and External-inner } \\
\text { Transfer tool hander }\end{array}$ \\
Tools & $\begin{array}{l}\text { Helical milling tool with two inner-cooling } \\
\text { holes }\end{array}$ \\
Speed & $\begin{array}{l}\text { 1300 rpm } \\
\text { Temperature } \\
\text { measurement }\end{array}$ \\
\hline
\end{tabular}

Fig. 4 Location of monitoring surface

Table 3 Tool parameters

\begin{tabular}{cc}
\hline Parameters & Details \\
\hline Diameter & $6 \mathrm{~mm}$ \\
Length of outlet & $9 \mathrm{~mm}$ \\
Length of overall & $55 \mathrm{~mm}$ \\
First clearance angle & $42.5\left(^{\circ}\right)$ \\
Number of teeth & 4 \\
\hline
\end{tabular}

at the outside of the hole, can be completely collected by the exhaust hood no matter with or without the pressurized air flowing into cutting areas(ESA and ES). However, all the chip was piled up around the hole under NES condition. These results show that the designed exhaust hood had a good chip collecting ability. 

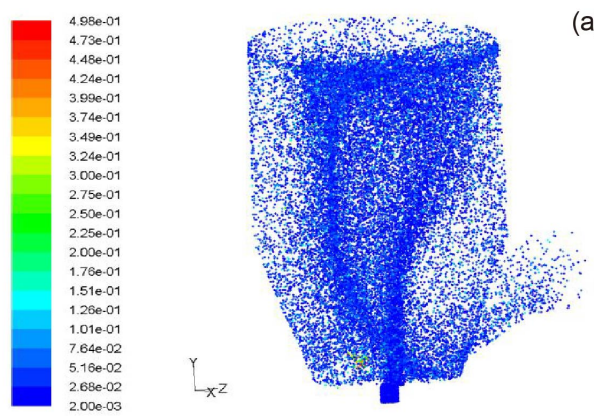

(a)
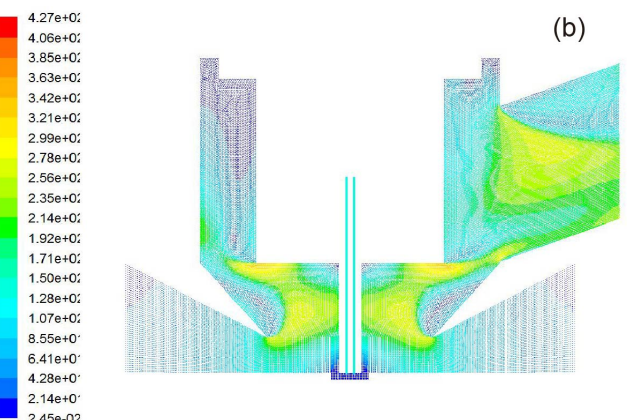

Fig. 5 Simulation process: (a) Particle tracking (b) Air velocity

Table 5 Chip removal conditions used in helical milling experiments

\begin{tabular}{|c|c|}
\hline Conditions & Details \\
\hline $\begin{array}{l}\text { Condition } 1 \\
\text { ESA }\end{array}$ & $\begin{array}{l}\text { The designed exhaust hood system with } \\
\text { the pressurized air flowing into cutting ar- } \\
\text { eas(exhaust hood system with pressurized air, } \\
\text { ESA) }\end{array}$ \\
\hline $\begin{array}{l}\text { Condition } 2 \\
\text { ES }\end{array}$ & $\begin{array}{l}\text { The designed exhaust hood system without the } \\
\text { pressurized air (exhaust hood system without } \\
\text { air , ES) }\end{array}$ \\
\hline $\begin{array}{l}\text { Condition } 3 \\
\text { NES }\end{array}$ & $\begin{array}{l}\text { Without any external chip removal system(dry } \\
\text { drilling without exhaust hood system,NES) }\end{array}$ \\
\hline
\end{tabular}

\subsection{Cutting forces}

Fig. 11 shows the cutting forces under different chip removal conditions(NES,ES,ESA). In the stage of CFRP helical milling, the axial forces $\left(\mathrm{F}_{z}\right)$ pxroduced by the different conditions are similar, but the radial forces calculated by equation (1) produced by ESA is much lower than that produced by other two conditions. The forces, in the stage of titanium alloys milling, can be generally ranked in a decreasing order : NES $>$ ES $>$ ESA. There is a larger difference in cutting forces between these three chip removal conditions when milling of titanium alloys than that when milling of CFRP. It may be related to the different milling sequence. Titanium alloy plate was placed under CFRP, therefore, the hole depth in the stage of milling titanium is larger than that in milling CFRP. A larger hole depth would impede chip removal, leading to serious tool wear and higher cutting force.

$F=\sqrt{F_{x}^{2}+F_{y}^{2}}$

\subsection{Cutting temperature}

Cutting temperature was measured using thermocouple, as shown in Fig. 9. The temperature signals are shown in Fig. 12. As cutting area was close to the thermocouple, the temperature increased with the excitation of machining. The highest value is regarded as the cutting temperature. Fig.
12 shows the measured temperature under different chip removal conditions. The effect of the chip exhaust hood on cutting temperature is evident. In the process of cutting titanium alloys, the cutting temperatures under ES and ESA were almost the same and are about $30.5 \%$ lower than that under NES. In the process of metal cutting, most of the cutting heat is carried by chip [22]. Therefore, prompt removal of chip can reduce heat accumulation in cutting areas, which resulted in a reduction of the cutting temperature. More importantly, the pressurized air in NES can further increase heat dissipation, which facilitated that the lowest temperature was delivered by the ESA condition. Compared to the temperature in cutting metals, the temperature in machining CFRP is much lower, while NES still produced the highest temperature, but the other conditions are almost at the same level.

\subsection{Hole quality}

\subsubsection{Hole size}

The diameter measurements were conducted on the middle part of the hole. The measured depth for the holes on titanium alloy and CFRP were $5 \mathrm{~mm}$ and $2.5 \mathrm{~mm}$, respectively. Fig. 13 shows the diameter variation of the hole. The hole diameter under ESA condition remained stable for both materials and the variation is minimal. The hole diameter under ES condition fluctuates for both materials. The hole diameter under NES condition showed a decreasing trend for both materials. In addition, the differences among the conditions at the stage of drilling titanium alloy are more significant than those at the stage of drilling CFRP. Therefore, ESA and ES can reduce the variation in the hole diameter.

\subsubsection{The burr size of hole exit on titanium alloys}

Fig. 14 shows the exit morphologies of the 10th hole on a Ti6Al4V plate. NES condition has larger width of hole exit 


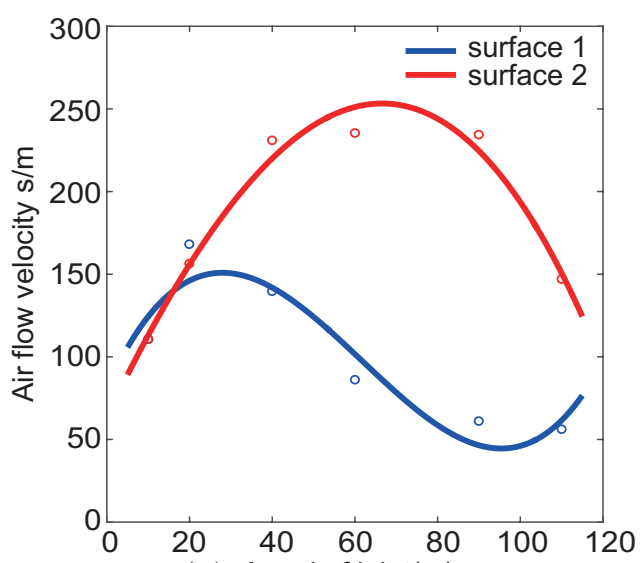

(a) Angel of inlet $\left({ }^{\circ} \mathrm{C}\right)$

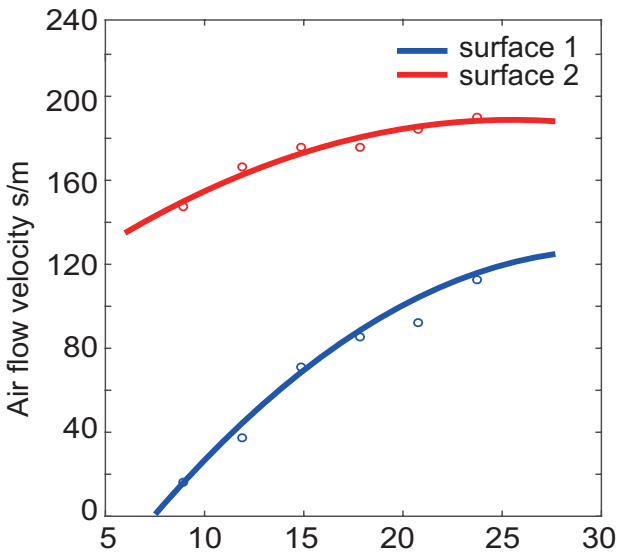

(c) Height of inlet(mm)

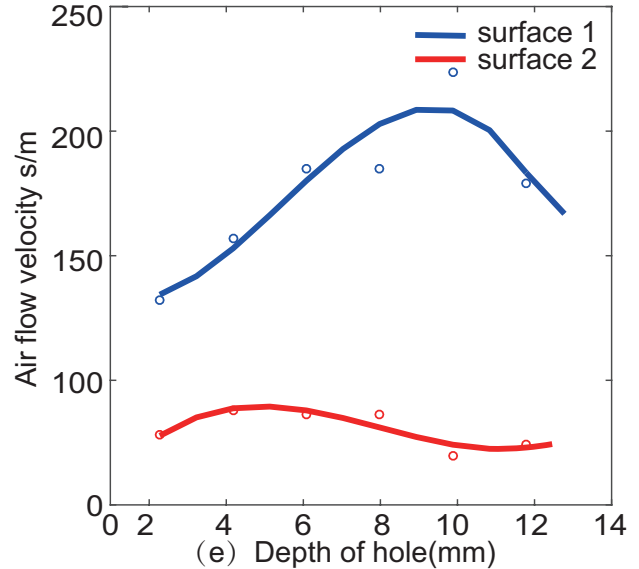

Fig. 6 Model parameters of the exhaust hood

burr, while ES and ESA conditions produced smaller width burrs. Similar trend for tool wear was observed for these conditions. The results show that the quality of the burr size of hole exit on titanium alloys, under ESA and ES conditions, are better than that under NES condition.

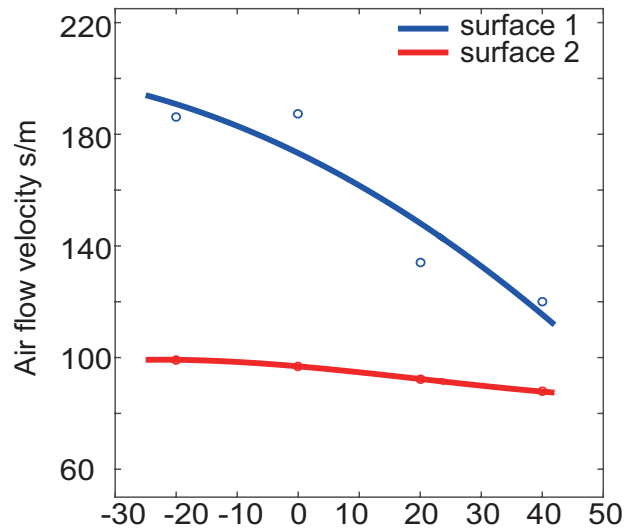

(b) Angel of outlet $\left({ }^{\circ} \mathrm{C}\right)$

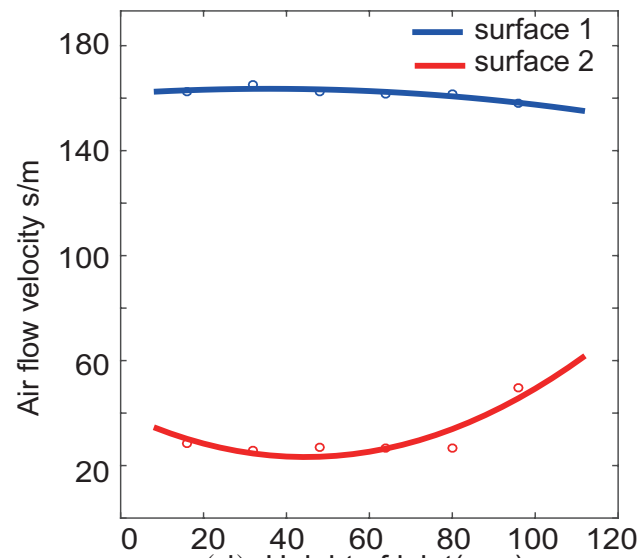

(d) Height of inlet $(\mathrm{mm})$

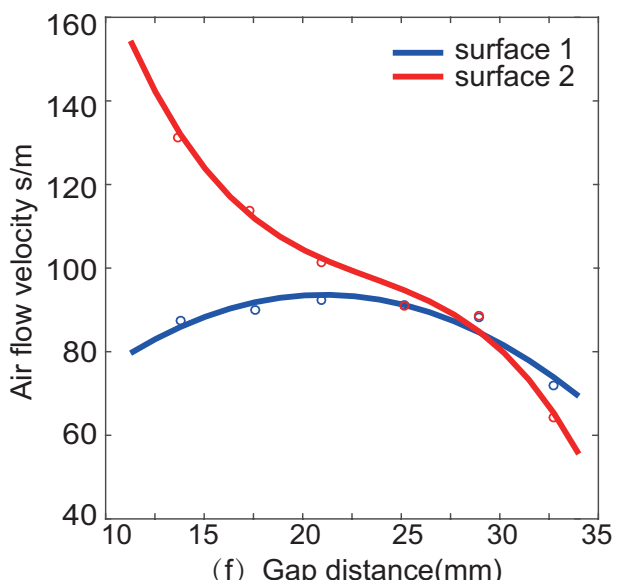

(f) Gap distance $(\mathrm{mm})$

\section{Discussion}

Owing to the discontinuous chip, helical milling has a better chip removal ability than conventional drilling. However, the eccentric distance between cutting tool and the hole still cause some problems in chip removal.

As we know, in helical milling, chip is mainly moved out from the hole through tool spiral flutes. But in the vertical hole-making process, the chip would be piled up around the 


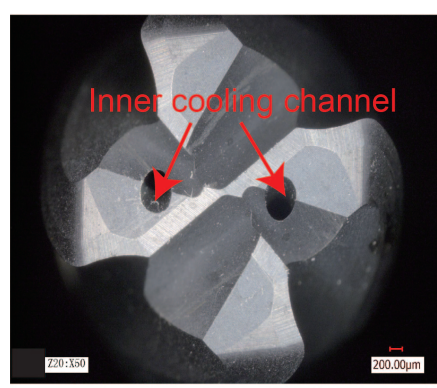

(a)

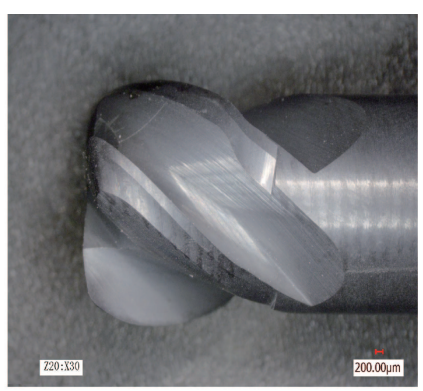

(b)
Fig. 7 Tool with inner cooling channel

hole bottom. Due to the actions of the tool friction and cutting vibration, some chip return into the hole, which is called chip returning phenomenon, as illustrated in Fig. 14 by the red path. Besides, in chip removing process, under the action of centrifugal force caused by high spindle speed, part of chip could get off tool flute and remain in the hole, which is called chip remaining phenomenon, as shown in Fig. 15 by the green path.

The remaining chip in the hole are hard to be removed out and would influence the cutting process. Due to the high chemical reactivity of titanium alloy and the high hardness of carbon fiber [23], the remaining chip would definitely cause adverse effect on tool wear. Fig. 16 shows the tool wear morphologies under different chip removal conditions after milling the 10th hole. Adhesive wear is the main wear mechanism for all conditions. The flank wear was measured, and the results are shown in Fig. 16. It can been seen that NES condition produced the most serious tool wear, then followed by ES condition and ESA condition delivered the smallest wear.

Owing to the vacuum pump, ESA and ES conditions can easily clear the chip around hole entrance (as shown in Fig. 10). Therefore, chip returning phenomenon was largely avoided and the tool wear was reduced. However, the airflow produced by the vacuum pump was hard to go into the hole. The negative pressure can only collect chip but has little effect on promoting chip removal in the hole. Obvious Ti6Al4V adhesion still occurred on tool surface under ES as shown in Fig. 16.

For ESA condition, the result of chip collection is similar with ES condition, while the pressurized air effectively promoted the residual chip to be removed out of the hole, thus the disadvantages caused by residual chip can be avoided and the ESA condition produced the smallest tool wear. More importantly, the pressurized air can largely increase heat dissipation in the cutting region, which also makes a great contribution to he reduction of tool wear.

It is well known that the cutting performance is strongly related to tool wear. Therefore, the ranking of cutting forces and hole qualities for these three conditions(NES,ES,ESA) are basically consistent with the degree of tool wear. In general, the designed hood has a good ability to collect chip and allow pressurized air to flow into the hole, which largely improved the quality of chip removal and provided cooling effect to the cutting tool. Based on these results, ESA condition is an effective method to improve the process of helical milling of CFRP/Ti.

Besides, it seems that the difference in cutting behaviors, such as cutting forces(Fig. 11), hole diameters(Fig. 13) and burr size (Fig. 14), between the three conditions for machining of titanium alloys than that for machining of CFRP, which is deemed to be related to the different cutting depth. Ti6Al4V plate was placed under CFRP. With the increasing hole depth, chip removal became more difficult, which lead to more remaining chip in the hole. This indicated that, in helical milling of deeper holes, the effect of ESA would be more obvious.

\section{Conclusions}

An exhaust hood was designed to collect chip in helical milling of CFRP/Ti stacks and its performance was evaluated. The following conclusions can be drawn from the experiment and simulation results:

(1) From simulation results, a larger inlet height and a smaller outlet angle can increase the airflow velocity around hole entrance and improve the chip collecting ability. The gap distance between the hood and the workpiece should be kept in a low level. Considering the tool holder and the installing conditions, the optimized hood geometry is as following: an inlet angle of $40^{\circ}$, an outlet angle of $20^{\circ}$, an inlet height of $24 \mathrm{~mm}$, an outlet height of $38 \mathrm{~mm}$ and a gap distance of 15 $\mathrm{mm}$.

(2) Together with a vacuum pump, the designed exhaust hood can collect the chip clearly in helical milling of CFRP/Ti when the gap distance is kept below $20 \mathrm{~mm}$. Even without pressurized air pumped into the hole, the system still can prevent chip escaping.

(3) Combined with pressurized air pumped into the hole, the chip removal system showed the highest chip removal ability and produced the smallest cutting force, the lowest cutting temperature, the best hole quality and the least tool wear compared to NES and ES condition.

(4) In helical milling of CFRP/Ti stacks, chip returning phenomenon and chip remaining phenomenon lead to lots of residual chip in the hole and increased tool wear. The chip removal system promptly cleared the chip around hole entrance and prevent chip returning to the hole, while the pressurized air pumped into the hole by the inner cooling channel of cutting tool accelerated residual chip to be removed out and increased heat dissipation in the cutting region. Therefor, the chip removal system with the pressurized air has the 


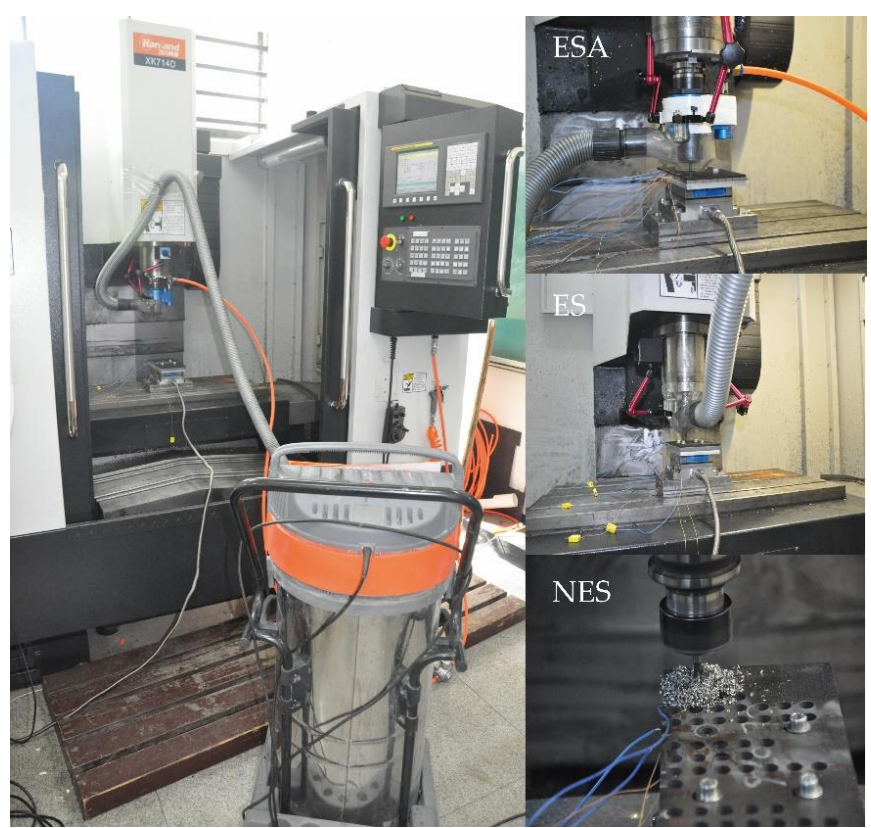

Fig. 8 Experiments with different cooling conditions

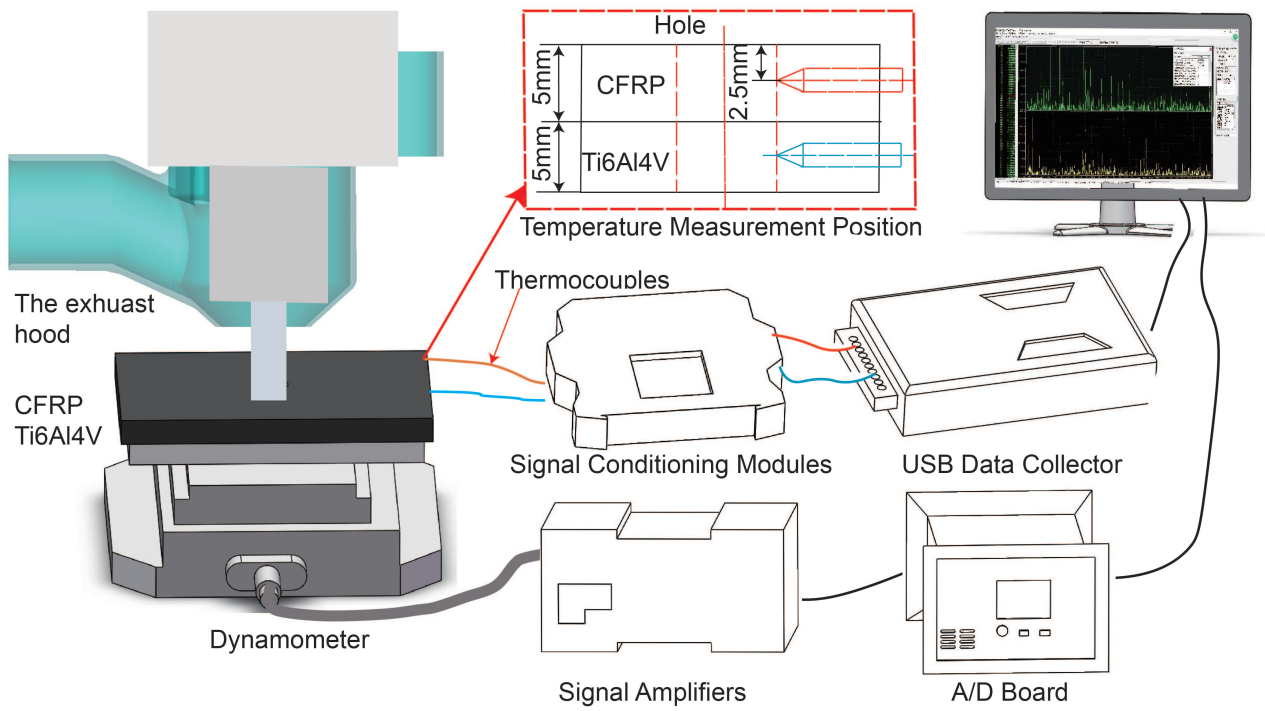

Fig. 9 Working principle of cutting force and temperature measurements
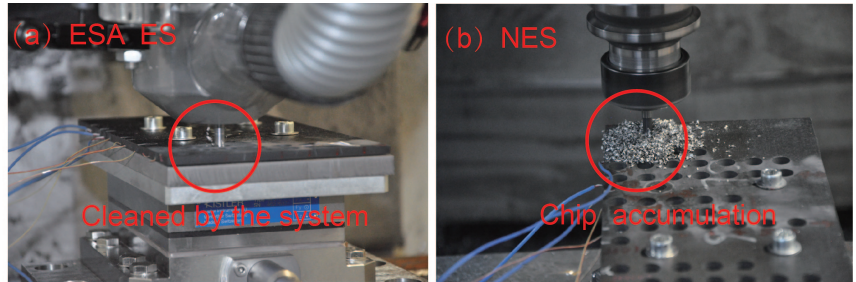

pressure and the pressurized air pressure was not considered In addition, injecting liquid nitrogen can have better cooling effect and help to reduce titanium adhesion on cutting tool. Therefore, more details about improving chip removal method in helical milling of CFRP/Ti need be systematic researched in the future.

Fig. 10 Path of dust under different conditions

best performance.

It is noted that the exhaust hood optimization only involved in limited parts and the relationship between the vacuum
Acknowledgements This work was supported byNational Key Research and Development Program(2017YFE0111300), the National Natural Science Foundation of China (51605326), the Natural Science Foundation of Tianjin (17JCQNJC04000) and the National Commercial Aircraft Manufacturing Engineering Technology Research Center Innovation Foundation (COMAC-SFGS-2018-36794). 

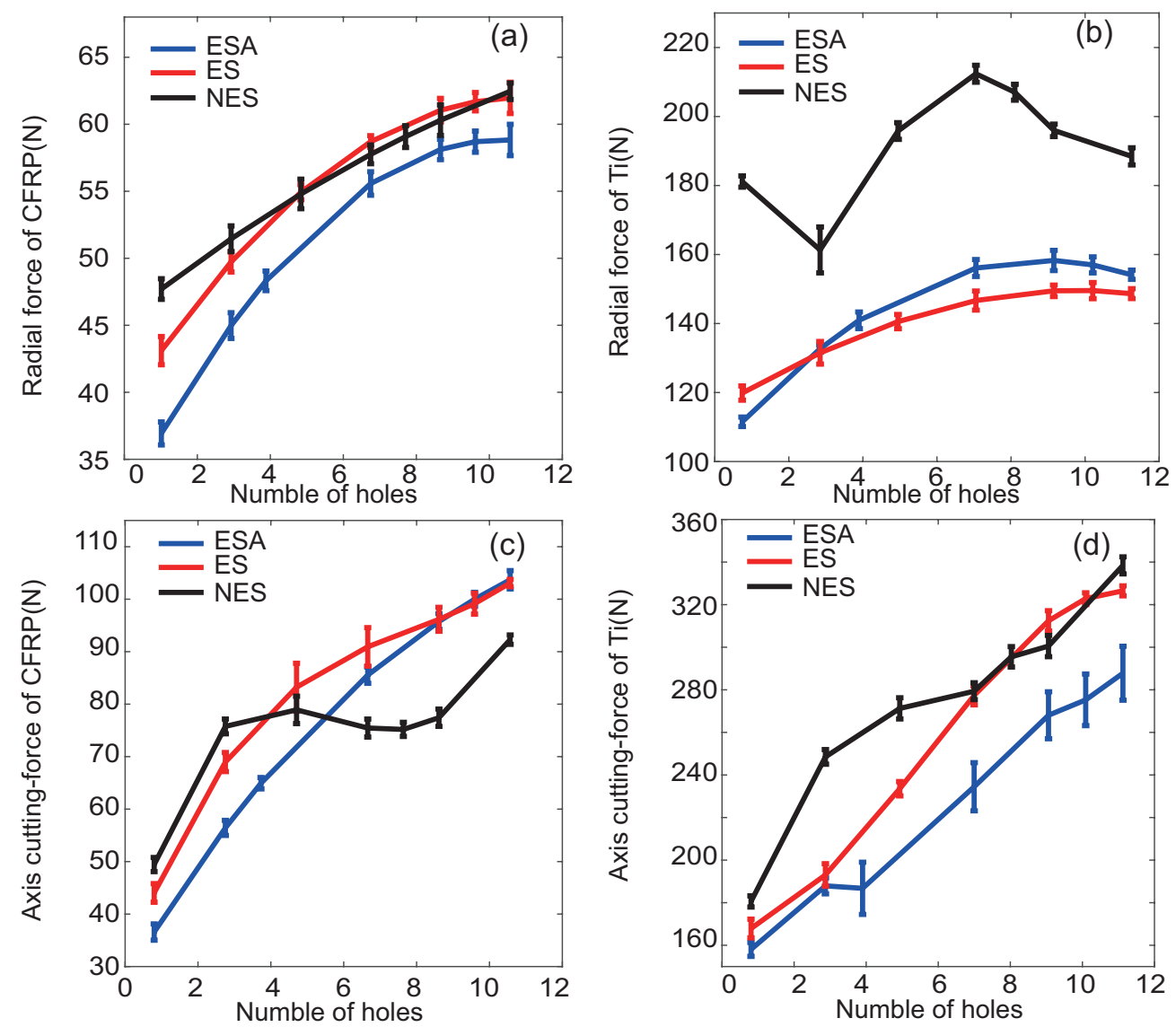

Fig. 11 Cutting force under different conditions
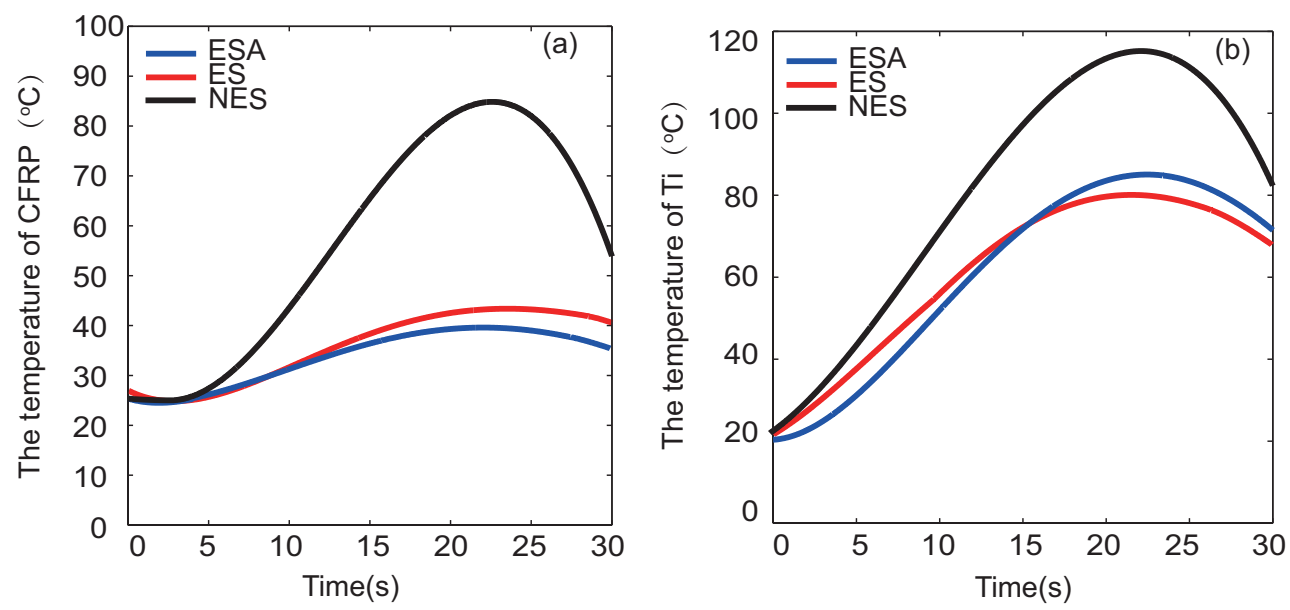

Fig. 12 Cutting temperature under different conditions

\section{References}

1. Xu J, Mkaddem A, El Mansori M (2016) Recent advances in drilling hybrid frp/ti composite: A stateof-the-art review. Composite Structures 135:316-338, DOI 10.1016/j.compstruct.2015.09.028

2. William G Roeseler, Branko Sarh, Max U Kismarton The Boeing Company (ed) (2007) COMPOSITE

\section{STRUCTURES: THE FIRST 100 YEARS}

3. Lan Zhou, Yinglin Ke, Huiyue Dong, Zupeng Chen, Kaiye Gao (2016) Hole diameter variation and roundness in dry orbital drilling of cfrp/ti stacks. The International Journal of Advanced Manufacturing Technology 87:811-824, DOI 10.1007/s00170-016-8528-1

4. Rajmohan T, Palanikumar K (2013) Modeling and analysis of performances in drilling hybrid metal matrix 

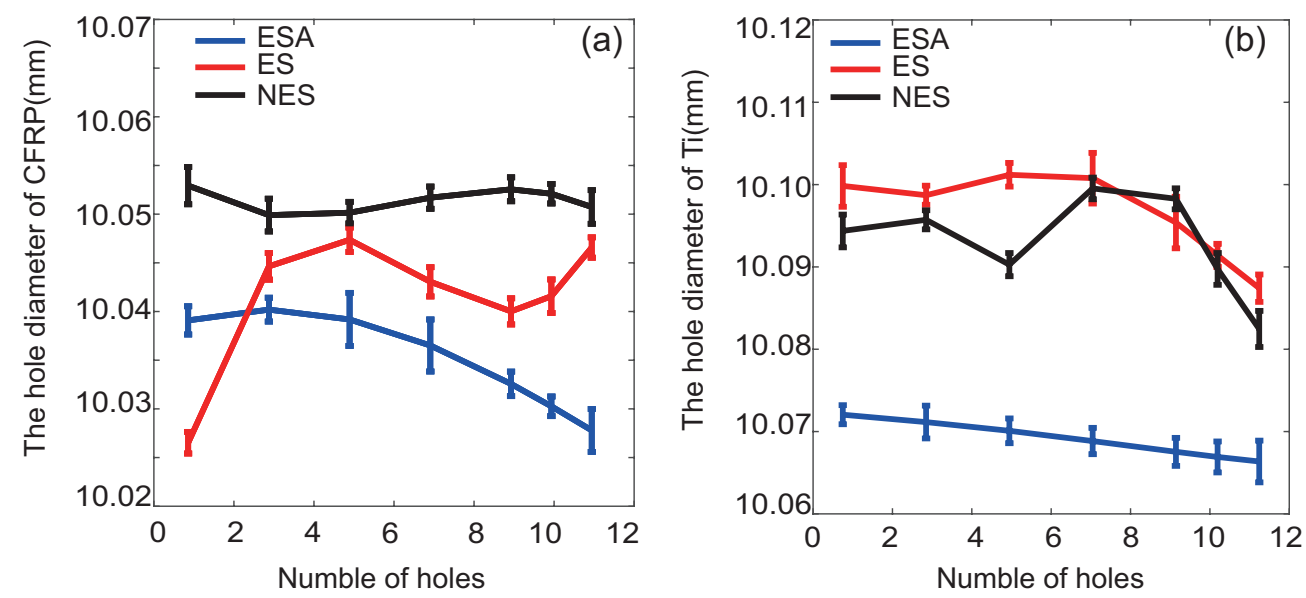

Fig. 13 Variation in the hole diameter under different processing conditions
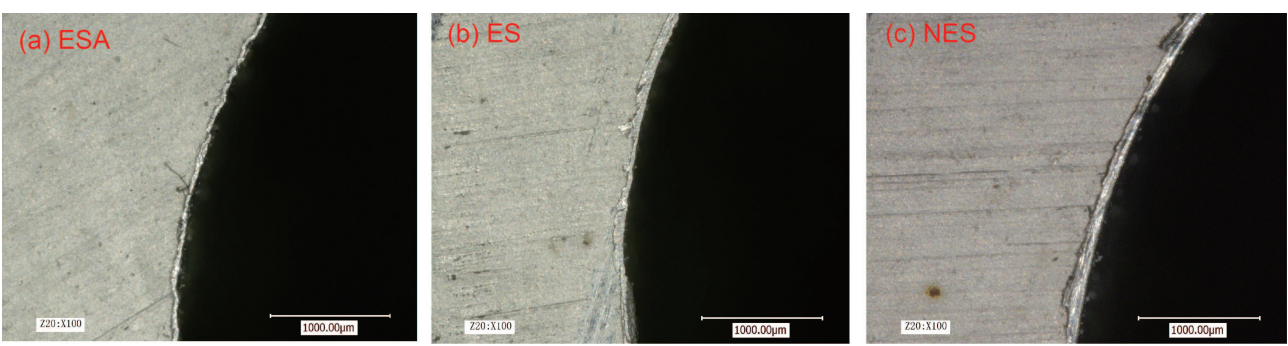

Fig. 14 Exit burr under different conditions after drilling the 10th hole

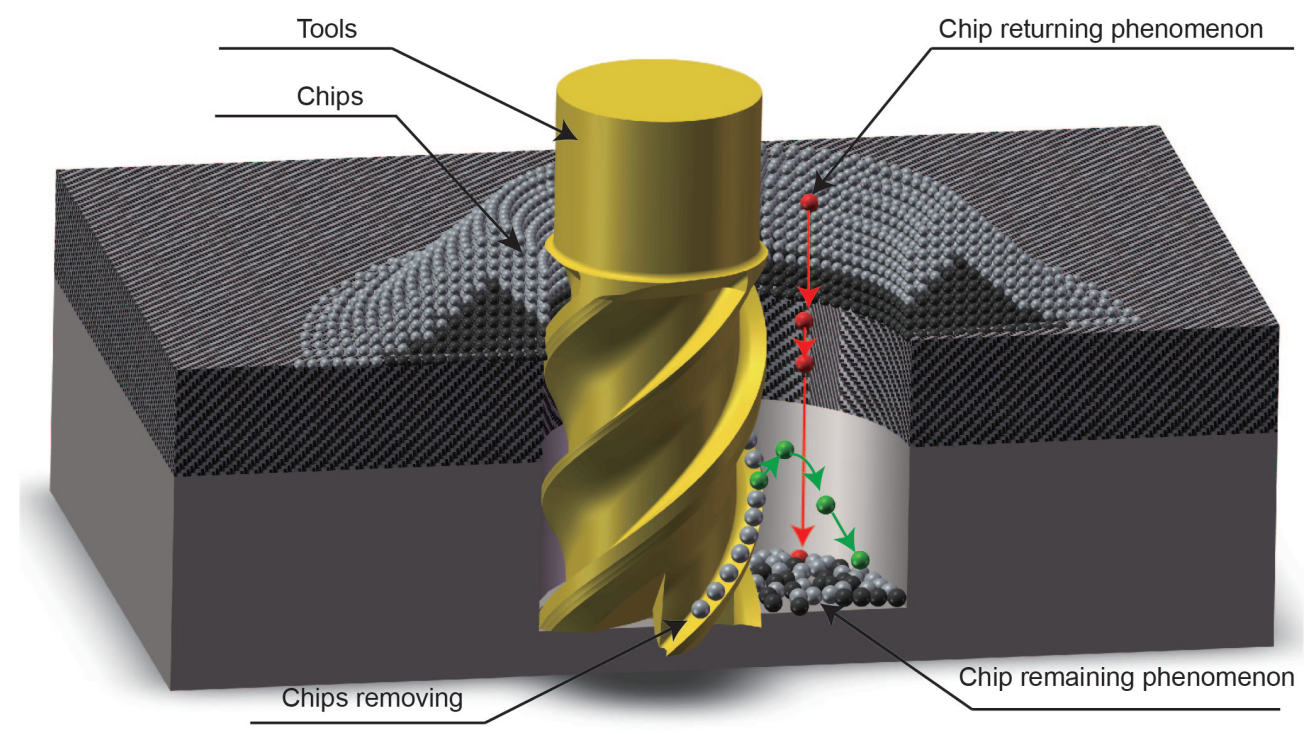

Fig. 15 Chips in the vertical hole-making process

composites using d-optimal design. The International Journal of Advanced Manufacturing Technology 64(912):1249-1261, DOI 10.1007/s00170-012-4083-6

5. Xu J, El Mansori M (2016) Numerical studies of frictional responses when cutting hybrid cfrp/ti composite. The International Journal of Advanced Manufacturing Technology 87(1-4):657-675, DOI 10.1007/ s00170-016-8512-9
6. Mizobuchi A, Aziz MSA, Izamshah R, Ishida T (2018) Chip discharge performance of micro-hole drilling through a glass plate using an electroplated diamond tool with different drill bits. International Journal of Precision Engineering and Manufacturing 19(9):12731280, DOI 10.1007/s12541-018-0151-7

7. Li H, Qin X, He G, Jin Y, Sun D, Price M (2016) Investigation of chip formation and fracture toughness in 

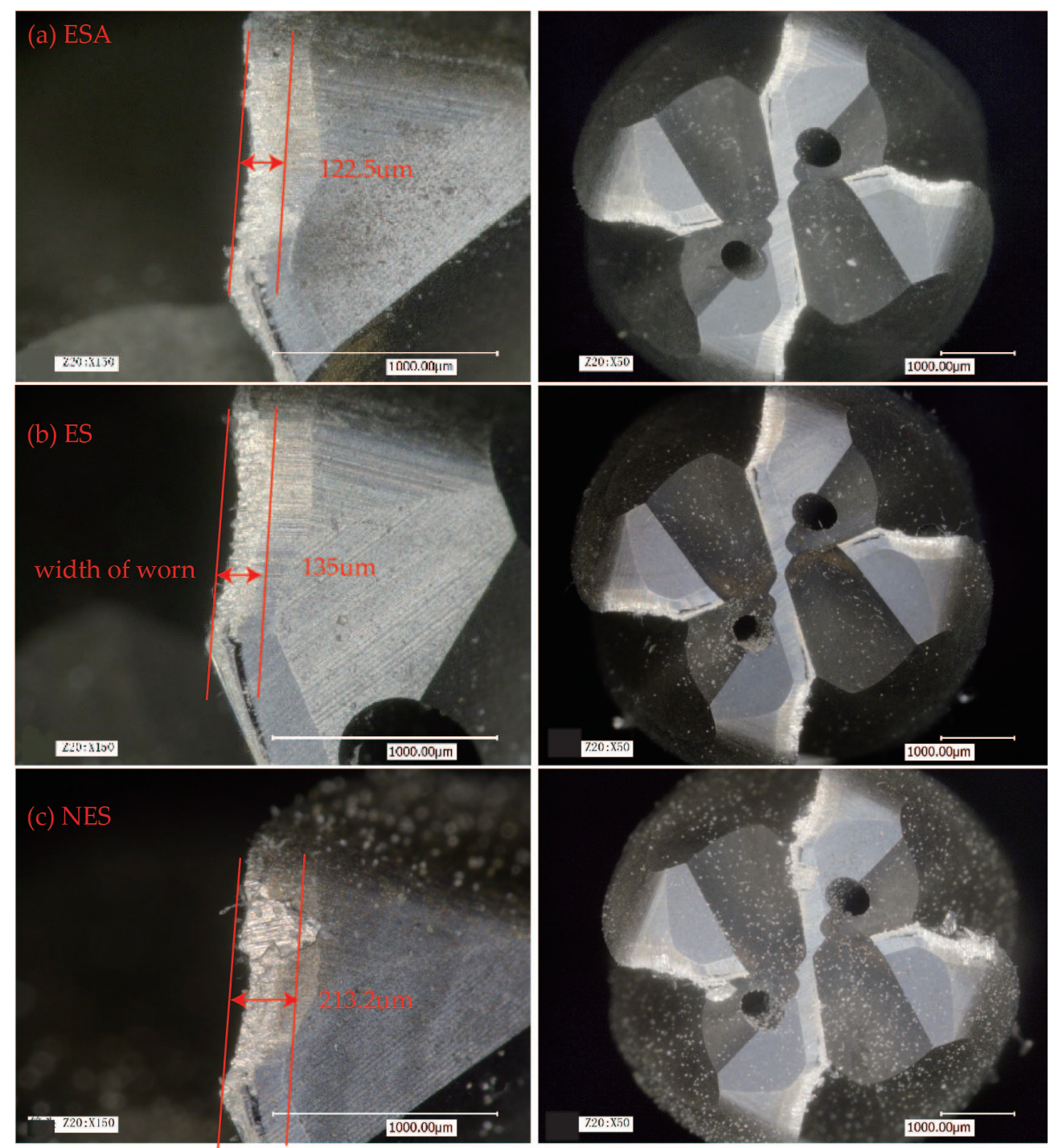

Fig. 16 Tool wear under different conditions after drilling the 10th hole

orthogonal cutting of ud-cfrp. The International Journal of Advanced Manufacturing Technology 82(5-8):10791088, DOI 10.1007/s00170-015-7471-x

8. Zhongyi ZHANG, Xiuling WANG, Leiguang LIN, Shudong XING, Yonghui Wu, Yao LI, Lijie $\mathrm{Wu}$ and Baoqi GANG (2001) The effects of carbon fibre and carbon fibre composite dusts on bronchoalveolar lavage component of rats. Journal of Occupational Health 43:75-79

9. IEEE CYBER 2015 Publication Committee (ed) (2015) Influence of Metal Chips on Drilling Quality of Carbon Fiber Reinforced Plastic and Titanium Stacks, IEEE, Piscataway, NJ, URL http://ieeexplore. ieee.org/servlet/opac?punumber $=7274858$

10. SenthilKumar M, Prabukarthi A, Krishnaraj V (2013) Study on tool wear and chip formation during drilling carbon fiber reinforced polymer (cfrp)/titanium al- loy (ti6al4v) stacks. Procedia Engineering 64:582-592, DOI 10.1016/j.proeng.2013.09.133

11. JI Chun-hui, Tian Li-cheng, QIN Xu-da,LIU Zhengwang, LIU Jie (2015) Processing quality comparison of holes in titanium alloy made by helical milling and traditional drilling. Materials for Mechanical Engineering 39(5):1-9

12. Liu C, Wang G, Dargusch MS (2012) Modelling, simulation and experimental investigation of cutting forces during helical milling operations. The International Journal of Advanced Manufacturing Technology 63(912):839-850, DOI 10.1007/s00170-012-3951-4

13. Haiyan W, Xuda Q (2016) A mechanistic model for cutting force in helical milling of carbon fiber-reinforced polymers. The International Journal of Advanced Manufacturing Technology 82(9-12):1485-1494, DOI 10. 1007/s00170-015-7460-0 
14. Ji C, Li Y, Qin X, Zhao Q, Sun D, Jin Y (2015) 3d fem simulation of helical milling hole process for titanium alloy ti-6al-4v. The International Journal of Advanced Manufacturing Technology 81(9-12):1733-1742, DOI 10.1007/s00170-015-7323-8

15. Pereira RBD, Brandão LC, de Paiva AP, Ferreira JR, Davim JP (2017) A review of helical milling process. International Journal of Machine Tools and Manufacture 120:27-48, DOI 10.1016/j.ijmachtools.2017.05. 002

16. Pereira RBD, Leite RR, Alvim AC, de Paiva AP, Ferreira JR, Davim JP (2017) Multi-objective robust optimization of the sustainable helical milling process of the aluminum alloy al 7075 using the augmentedenhanced normalized normal constraint method. Journal of Cleaner Production 152:474-496, DOI 10.1016/ j.jclepro.2017.03.121

17. Impero F, Dix M, Squillace A, Prisco U, Palumbo B, Tagliaferri F (2018) A comparison between wet and cryogenic drilling of cfrp/ti stacks. Materials and Manufacturing Processes 33(12):1354-1360, DOI 10.1080/ 10426914.2018.1453162

18. Li Z, Zhang D, Qin W, Geng D (2016) Removal analyses of chip and rod in rotary ultrasonic-assisted drilling of carbon fiber-reinforced plastics using core drill. Journal of Reinforced Plastics and Composites 35(15):1173-1190, DOI 10.1177/0731684416644510

19. Liu M, Takagi J, Yanagida K (2004) A study of the chip formation and chip removal in dry drilling of aluminum cast alloy. Key Engineering Materials 257-258:575-0, DOI 10.4028/www.scientific.net/KEM.257-258.575

20. PETER S THORNE*, KAREN H BARTLETT $\dagger$, JOHN PHIPPS and KATARINA KULHANKOVA (2003) Evaluation of five extraction protocols for quantification of endotoxin in metalworking fluid aerosol. The Annals of Occupational Hygiene 47(1):31-36, DOI 10.1093/annhyg/meg009

21. Bi Z (2011) Design and simulation of dust extraction for composite drilling. The International Journal of Advanced Manufacturing Technology 54(5-8):629638, DOI 10.1007/s00170-010-2971-1

22. Wang H, Qin X, Li H, Tan Y (2016) A comparative study on helical milling of cfrp/ti stacks and its individual layers. The International Journal of Advanced Manufacturing Technology 86(5-8):1973-1983, DOI 10.1007/s00170-015-8296-3

23. M Ramulu , T Branson, D Kim (2001) A study on the drilling of composite and titanium stacks. Composite Structures 54:67-77, DOI 10.1016/S0263-8223(01) 00071-X 